\title{
Using Guidelines from Cognitive Load Theory for the Traditional/Online Flipped Classroom Approach
}

\section{Prof. John M. Santiago Jr., Colorado Technical University}

Professor John Santiago has been a technical engineer, manager, and executive with more than 26 years of leadership positions in technical program management, acquisition development and operation research support while in the United States Air Force. He currently has over 16 years of teaching experience at the university level and taught over 40 different graduate and undergraduate courses in electrical engineering, systems engineering, physics and mathematics. He has over 30 published papers and/or technical presentations while spearheading over 40 international scientific and engineering conferences/workshops as a steering committee member while assigned in Europe. Professor Santiago has experience in many engineering disciplines and missions including: control and modeling of large flexible space structures, communications system, electro-optics, high-energy lasers, missile seekers/sensors for precision guided munitions, image processing/recognition, information technologies, space, air and missile warning, missile defense, and homeland defense.

His interests includes: interactive multimedia for e-books, interactive video learning, and 3D/2D animation. Professor Santiago recently published a book entitled, "Circuit Analysis for Dummies" in 2013 after being discovered on YouTube. Professor Santiago received several teaching awards from the United States Air Force Academy and CTU. In 2015, he was awarded CTU's Faculty of the Year for Teaching Innovations. Professor Santiago has been a 12-time invited speaker in celebration of Asian-Pacific American Heritage Month giving multi-media presentations on leadership, diversity and opportunity at various military installations in Colorado and Wyoming.

\section{Dr. Jing Guo, Colorado Technical University}

Dr. Jing Guo is a Professor in Engineering Department at Colorado Technical University. She is the course director in circuits and electronics area. She taught variety of underrated and graduate courses including capstone design in Electrical and Computer Engineering area. 


\title{
Using Guidelines from Cognitive Load Theory for the Traditional/Online Flipped Classroom Approach
}

\author{
John Santiago, Jr., Ph.D. and Jing Guo, D.Eng. \\ Colorado Technical University (CTU), College of Engineering, Colorado Springs, CO
}

\section{Introduction}

The College of Engineering (CoE) developed a freshman-level course entitled, Introduction to Engineering (EE110) for both the Electrical Engineering and Computer Engineering undergraduate programs in preparation for an online flipped classroom approach. For the Faceto-Face (F2F) classroom, the flipped learning approach has been successfully implemented with EE 110 during the past few years [1] [2]. The labs in EE110 were identified as a challenge when the course will be delivered online [3]. Using interactive video and Google Docs were effective means in delivering the content [4] [5]. Although the creation and delivery of multimedia content was based on the years of teaching experience by $\mathrm{CoE}$, research studies provide a theoretical basis for the design, development and instructional delivery of the content. Specifically, research based on Cognitive Load Theory (CLT) appears to be consistent with the CoE's F2F teaching approach and experience. The paper shows how the instructional delivery of the EE110 content compares with some guidelines offered by CLT.

The CLT suggests evidence-based teachings for designing and delivering the instruction accounts for the limited capacity of working memory [6] [7]. The CLT also models the student's cognitive learning process and architecture for efficient learning. The paper summarizes CLT's key principles and guidelines. Key principles are illustrated with examples from EE110.

Appendix A provides several tables of student feedback and Appendix B lists abbreviations and acronyms used in this paper.

\section{CoE's Adult Learners and Teaching Experience of Full-Time Faculty}

The student body in the CoE consists mostly of adult learners who have family and are working full-time. To meet student and employer needs, the college successfully developed and implemented a program curriculum involving day and night classes in electrical engineering and computer engineering. The curriculum program consists of 11-week courses and allows a flexible schedule for students to successfully complete an ABET-accredited degree in either BSEE or BSCE. During 2017, CoE proudly received an ABET re-accreditation for six years with no required interim reports.

In 2015, the University tasked the CoE to develop a strategic plan in delivering online undergraduate and graduate engineering courses. Starting in April 2015, the college embraced a flipped learning approach for future and online delivery of undergraduate engineering courses. One reason for adopting flipped learning concerns the amount of time during a synchronous session when students and instructor are online together. The full-time faculty, consisting of 
four professors, determined that there is little time to deliver synchronous lectures online. However, when engineering content is delivered during an online synchronous session, $\mathrm{CoE}$ anticipates that more time is needed to address student questions on the multimedia content, assigned readings, homework and weekly lab experiments. The engineering faculty also wanted to have students practice on problem-solving techniques during the online synchronous session.

Another reason for adopting the flipped classroom is based on one of the authors' years of acquired experience in developing interactive and multimedia content suitable for e-books and online delivery. Multimedia content turns out to be a key component to the flipped classroom when students work individually on their own. The teaching approach attempts to leverage numerous technologies to translate the traditional ground or F2F teaching philosophy to one suited for the online classroom environment.

It should be noted that after developing the initial content during 2015 and refining the flipped learning content and delivery, the University postponed delivery of the EE 110 online course due to limited resources for the next two years. The time and effort of the full-time faculty was focused on preparing for the ABET visit during 2017. Plans and implementation for the delivery of a sequence of online engineering courses resumed in 2018.

\section{Description of EE110}

EE110 consists of basic electronics and weekly lab assignments. The introductory course attempts to prepare students who will be entering either the electrical or computer engineering programs. Table 1 shows the deployment of weekly F2F lab assignments.

The College of Engineering recognized online lab assignments will be the challenging part of the program curriculum [3]. This insight was verified and validated during a pilot program when the flipped classroom was implemented to mimic the online synchronous chat sessions. In this case, when students met in the classroom, it simulated the online chat session in two areas: (1) one chat session was

\begin{tabular}{|l|l|}
\hline Week \# & Lab Assignments \\
\hline Week01 & Circuits Laboratory Introduction \\
\hline Week03 & Digital I/O Circuits \\
\hline Week04 & Basic Gates Verification \\
\hline Week05 & Digital Simplification \\
\hline Week06 & Ohms Law \\
\hline Week07 & Complex Circuit Analysis \\
\hline Week08 & RC Circuits Multisim Simulation \\
\hline Week09 & Function Generator Assembly \\
\hline Week10 & Function Generator Testing \\
\hline
\end{tabular}

Table 1. EE110 Lab Schedule for addressing student questions on the multimedia content, readings, and homework problems; and (2) the other chat session addressed lab questions. Instructors observed how students conducted their labs experiments providing students guidance on how to go through the troubleshooting process. The instructors also observed that students collaborated with each other when troubleshooting their circuits.

If the College of Engineering can effectively deliver the lab content with this first course to meet student outcomes, then the engineering faculty can expect the development of future electrical engineering courses involving lab activities to go much smoother.

Although the full-time engineering faculty has extensive experience teaching adult learners in F2F classroom, the faculty had no experience in developing and delivering a complete 
engineering course fully online in 2015. Because the engineering faculty has its primary focus on teaching, a full-time instructor carries a typical workload of four courses per quarter.

Consequently, each instructor has taught between thirty to forty different engineering courses including math and physics during their time in the CoE. During the development of EE110, the instructors have been downloaded to two to three classes for one year to focus on content creation and instructional delivery for the online environment.

\section{F2F Teaching Philosophy}

Typical engineering courses taught at the $\mathrm{CoE}$ are two to three hours long meeting twice a week in a physical classroom. The teaching pedagogy uses a student-centered approach. Students actively participate in their learning as opposed to listening to several passive one-hour lectures in class.

Based on the authors' experience, providing a one-hour lectures is inefficient, especially when it comes to the student body at the CoE. With most of the students who are working adults with family and kids, they usually work during the whole day and come to school at night. A two or three-hour lecture during the evening class will lead them to becoming disengaged and in extreme cases, fall asleep. It was found that short five to fifteen-minute lectures followed by short exercises completed by the students achieve better learning outcomes with a more engaging learning experience.

For example, one approach of instruction involves solving numerous engineering problems such as circuit analysis or signals and systems. In this context, the teaching approach entails the following steps:

- Step 1. Introduce an engineering topic for 5 minutes. Motivate why this topic is important and relevant...keeping it short and sweet. Show how information will benefit students or tell an appropriate 'war story' based on industry experience.

- Step 2. Solve and work out an example analytical problem. The activity usually takes 5 to 15 minutes depending on the complexity of the problem.

- Step 3. Have students struggle with another similar problem for 10-15 minutes, either individually or in pairs.

- Step 4. Solve problem together (10-15 minutes). An instructor can have one of the students solve the problem on the whiteboard and appropriately guide the student to unravel the problem requesting feedback from other students as well.

- Step 5. Take a break for 5-15 minutes and repeat for the next hour.

The above approach is not set in stone. The instructor can adapt the delivery of the material while addressing any student questions or reinforcing concepts for the next hour. For example, an instructor may have a short lab or hands-on exercise using Matlab/Simulink or PSPICE to emphasize the concept taught during the first hour. The CoE's pedagogy is consistent with past teaching philosophies [8] [9] [10].

So how does one translate, the F2F teaching that proved successful in the past to one that is suitable for online delivery? One approach leverages available technologies to emulate the successful active and student-centered learning philosophy found in the F2F classroom. In 
addition, the content developed for flipped learning can be used to transition from F2F course to a fully online version. Once the online content becomes suitable for the F2F flipped learning, then the content would be suitable for the online environment supplemented with frequent online synchronous sessions and other online learning activities.

\section{Flipped Learning}

In the digital and internet marketing world, "Content is King," as written by Bill Gates in 1996. And with the flipped classroom approach, this is no exception. Engaging and interactive multimedia content serves as a key component for the flipped classroom. The authors believe that this is especially true if a student decides to take an undergraduate degree that is delivered fully online for several years.

For an optimum learning experience, there must be a tight and integrated link with work done by students at home and work they do in class [11] [12]. This idea applies to a synchronous and online group session. For the F2F flipped learning, a professor must maintain alignment when there is a blend of online and in-class activities for a specific learning activity. That is, both activities are supplementary and not complementary. The authors see the online activities tailored for individual work as preparation for the group activities conducted through either the F2F or online synchronous meetings. During the group activity, the most complex or deep learning tasks can take place [12].

To set up the group activity, the professor can start off with a review to connect concepts studied that took place during the individual space online (e.g. viewing videos and taking frequent quizzes). Another alternative is to ask a challenging question to prepare the student's frame of mind for group activity.

Finally, an important point is to build individual accountability for each student. For example, students may be asked to view a YouTube video as an individual activity. To provide student accountability, each student must summarize on what they viewed and then post their reflective comments on an online discussion board. For even greater accountability, each student is then asked to formulate a discussion question and be prepared to lead a 10-15 minute in-class group discussion. This approach was successfully used in a senior-level course on digital communications [11]. The accountability requires student reflection to provide a productive learning experience when the students meet in a group setting. The professor can then randomly select or solicit a student volunteer to lead the discussion.

The F2F learning is a more expensive mode of communication when compared to online communication. F2F learning requires both instructor and students to be physically together. In a F2F environment, learners must work together at the same time and place, to reach a common understanding of what is to be learned. In an online environment that is asynchronous, learners do not have the constraints of time and place. By leveraging online technologies, student learning should be designed with transfer of same information to all learners. For the freshman student, online learning is most suitable for factual type learning or less challenging learning activities [12]. 
F2F would be recommended for intensively challenging, high-benefit learning activities. For example, the hands-on laboratory experiments in EE110 solidify key concepts learned from the multimedia content: online videos, text readings, assigned homework and frequent online quizzes. Through peer collaboration, students can help each other work through the labs as well as learning how to troubleshoot their circuits with instructor guidance.

Another consideration when using the flipped learning philosophy is student workload. The online activities should not provide additional work found in a traditional F2F classroom. To account for student workload, the online activities performed individually should be well integrated with the F2F group activity or the online synchronous group session [12].

Flipped learning combines active problem-solving activities and direct instruction/mastery learning activities. These core activities provide a coherent and meaningful learning experience [12]. However, the professor needs to address student's potential fear or resistance to the new method. This point may have not been emphasized to students for EE110 during 2016 when the course was flipped and is a lesson learned for the authors.

Based on the EE110 experience, not only do professors need a variety of teaching instruments to evaluate higher-order thinking skills, like: critical and creative thinking skills, problem-solving, and content mastery, they also need to be aware of Cognitive Load Theory (CLT).

\section{Key Concepts in Cognitive Load Theory (CLT)}

The professor's teaching can use CLT by accounting for the student's cognitive architecture. Knowing how a student processes information, can enhance the learning experience whether the course content or instruction is delivered either by means of online multimedia and social-media learning or F2F group learning.

In CLT, there are two types of memory, long-term memory and short-term (or working) memory. Long-term memory has unlimited capacity while working memory has very limited capacity. Working memory is limited when holding and processing new information. In working memory, five to nine chunks of information appear to be its holding capacity before it becomes overloaded. Also, working memory has a limited lifetime for retention (e.g. thirty seconds to two minutes). [12]

The three main concepts of CLT are: schemas, types of cognitive load, and dual processing channels (i.e. audio and visual channels).

Schemas. So how does learning takes place as information is transferred into long-term memory? The learner must create connections between new information found in short-term or working memory and existing information stored in long-term memory to build upon a schema or create a new schema. Schemas are complex patterns of information stored in long-term memory. Schemas are basically mental structures to organize knowledge. In addition, longterm memory can hold vast amount of complex data organized through an infinite number of stored schemas. The student can automatically retrieve the schema from long-term memory necessary to accomplish a given task. A student knows a concept and learned its content when the corresponding schema is stored in long-term memory. 
For example, one schema concerns an individual driving a car when traveling from one familiar place to another, such as, weekly driving to work from an individual's home residence. The individual does not need an instruction manual or a map to get to work. In fact, the individual may be attentive enough to listen to the radio while safely driving to the destination. However, if the destination is unfamiliar, the driver turns off the radio and focuses more attentively on where the driver needs to go, resulting in developing a new schema. Another example is when a student can solve numerous engineering problems automatically and with relative ease. In this case, the student has acquired numerous schemas to become an expert in an engineering topic.

When a large schema is retrieved from long-term memory, the schema is treated as a single element in working memory. And when a large schema is treated as a single element, the faster the student can perform a given learning task. New information in working memory can be transferred and stored in long-term memory. The stored information can be later retrieved when needed. When the capacity of working memory is not exceeded, greater transfer of information can be stored into long-term memory.

Real learning takes place by altering the learner's schematic structure. When this change occurs, learners can grasp the information and process it within their working memory, and finally commit it to long-term memory. That is, they build upon previously learned information to expand their knowledge base.

Building schemas applies to both F2F and online learning environments. For example, Talbert relates CLT with flipped learning describing the pedagogy for both F2F and online environments [12]. On the other hand, Pappas [13], Hendricks [14], and Guyon [15] describe and apply CLT concepts focused for e-learners in corporate environments.

When cognitive overload occurs, learners will make more errors, become not fully engage and provide poor effort overall. The needed change in the schematic structures and pathways will not occur. Why? Simply because the learner did not have enough time or cannot process the information being offered within the lesson. Therefore, from an instructional design point of view, courses should be created in such a way that reduces the student's cognitive load. This reduction will give students' time and opportunity to process what is being taught more effectively and more easily.

In summary, the professor must design the content as well as its delivery to transfer the course content into the student's long-term memory through the development of schemas. Schema theory says that the student's expertise in any area is equivalent to the acquisition of schemas. In this case, knowledge and skills become automatic. Applying CLT allows the professor to design its course by building upon the student's informal knowledge, using existing schemas stored in student's long-term memory. If previous knowledge is not there, homework or other learning activities can be used to build the necessary knowledge in working memory that can be transferred into long-term memory as schemas [12].

Types of Cognitive Load. To efficiently design the delivery of content resulting in efficient learning, the professor needs to account for three types of cognitive load in working memory: 
extraneous cognitive load, intrinsic cognitive load and germane cognitive load [6] [7]. Knowing these types of load allows the professor to make optimal use of the student's working memory.

The first type is extraneous cognitive load. This load involves how the content (e.g. exam or question) is presented. You can reduce the load by using diagrams with text or using worked-out examples to show a student on how to solve a question. The extraneous cognitive load is a burden caused by unnecessary items that are not relevant to the learning experience but occupies working memory. Unnecessary information requiring extra mental processing includes: decorative pictures, animations, background music and others that are not relevant or add value to the learning experience.

Intrinsic cognitive load is the second type of cognitive load which deals with the built-in complexity of the material. The professor can reduce this type of load by splitting the task and using previous informal knowledge. Some tasks are more complex than others resulting in different levels of intrinsic cognitive load. The professor may not reduce the built-in complexity of the material, but what is important is how the course material is presented.

The last type of cognitive load is germane cognitive load requiring the learner to invest in time and effort. In this case, germane cognitive load builds new and automates new schemas. The more you can reduce extraneous and intrinsic load, the more resources are available for germane cognitive load in working memory to process the information and move into long-term memory. In other words, retention goes up by reducing extraneous and intrinsic load.

Audio and Visual Processing Channels [6] [7]. To help students learn efficiently by transferring information from working memory into their long-term memory, the professor must present the information by reducing non-relevant items (extraneous cognitive load). Built on CLT, efficient learning requiring significant cognitive processing can take place through the processing channels for verbal and visual material (or dual channels).

One experiment for the reader to show that two processors are needed for efficient learning is to find a narrated video and ask the following questions: Does the visual content make sense without the narration? Does the narration make sense without the visual content? Does the narrated video make sense resulting in more efficient learning? Hopefully, the last question is yes. If not, then one of the processors is redundant increasing cognitive load and making inefficient use of resources in working memory.

In summary, before CoE was aware of CLT, the creation and delivery of multimedia content for EE110 was based primarily on the CoE teaching experience. However, CLT appears to be consistent with the F2F and online teaching philosophy by the CoE. The authors agree that CLT provides evidence-based guidelines for designing and delivering instructions while accounting for the limited capacity of working memory [6]. CLT also leverages the learning process and cognitive architecture for efficient learning [6].

With CLT, there are numerous ways to use working memory for long-term storage and numerous ways to reduce cognitive load. By taking these factors into account, the student has more space in working memory. Consequently, the ease of learning can take place. 


\section{Reducing Cognitive Load for EE110}

What are some load reducing techniques? Examples of cognitive load reduction include the following [16]:

- Use symbols instead of photographs

- Use simple text on the screen

- Add sound effects to support on-screen animation

- Use a voice-over instead of text

- Frame video using the rule of thirds

The above examples can be explained by CLT principles. Discussed next are some principles developed by Clark, et al [6] [7], and Mayer [15] [17] to manage cognitive load. These learning principles include: modality principle, learner control, split attention, reversal effect, redundancy effect, and self-explanation/mental rehearsal (weekly quizzes and lab activities).

Modal Principle. Divide and spread the information so visual and audio channels are used to avoid overloading each channel. For example, if all the course content is visual with text, pictures, or animations, the visual channel becomes overloaded. The delivery of engineering content should offer some data verbally and other data visually to avoid exceeding the capacity of working memory. This will allow the learner to absorb information using different processing methods, which will reduce cognitive overload. Visual content with narration spreads the load between the two channels improving the processing capacity. This allows students to absorb information using different processing methods while reducing cognitive overload.

Given that CLT says that efficient learning takes place when both visual and audio processors in working memory is used, narrated videos were obviously developed. EE110 leveraged the modality principle by having over seventy YouTube short videos, totaling about nine hours. This averages about less than one hour of video instruction is needed for each week. A series of short videos were used throughout the 11-week course of instruction. These videos use both visual and audio narration providing efficient use of resources in working memory allowing students to learn and process the content more efficiently. Most of the seventy-plus videos in EE110 are less than ten minutes.

The reader may ask, 'what happen to the rest of the forty hours found in a traditional classroom?' The rest of the time is focused on learning activities to transfer and automate their understanding into long-term memory. These activities include: homework problems, quizzes and lab experiments. A series of short videos followed up with short assessment activities (e.g. quizzes) provided a means to avoid overloading working memory. In EE110, short videos were the norm to minimize the amount of extraneous cognitive load that is not of immediate interest to the learner and to make optimal use of working memory. A Harvard Study [18] shows that short videos are not enough. Students' attention will wander even for a short video. The professor needs to include assessment activities to keep students mind from wandering. In EE110, weekly 
practice quizzes and weekly final quizzes were used to help transfer knowledge from working memory into long-term memory. The videos and quizzes prepared students to perform weekly lab experiments promoting the development and automation of schemas.

When investigating on how to produce engaging videos back in 2008, Professor Santiago learned that entrepreneurs who are using videos to promote internet marketing or other affiliate products have been using Camtasia, produced by TechSmith. During 2015 when developing content for EE 110, the full-time faculty learned how to use Camtasia, a video capture and editing software tool for creating multi-media content. Camtasia has many features to cue and engage the student on important areas on the video. For example, a professor can use callouts to highlight areas on the video where students should focus their attention. Callouts are handy during the editing process when the professor forgets to use its mouse for highlighting areas within the video.

When the learning objective is competency in a technical task, it may be best to make a screencast where Camtasia excels [19]. The tool became one of the first and must-have video creation and video editing tool for the authors. Recently, other popular video editing software began incorporating this screen capture feature as well. However, Camtasia was originally targeted for the educational marketplace. Camtasia evolved from being a program for software demonstrations back in 2005 to a full-featured educational tool in 2015. Despite the large number of current features, its learning curve is manageable based on faculty use of Camtasia. Table 2 lists key educational benefits \& features of Camtasia.

\begin{tabular}{|c|c|c|}
\hline $\begin{array}{l}\text { Camtasia } \\
\text { Feature }\end{array}$ & Description & Educational Benefit \\
\hline a & Hot Spots & $\begin{array}{l}\text { Students can choose a particular learning path and interact with video by clicking on } \\
\text { buttons or characters. } \\
\text { Create attractive PowerPoint slides and import with Camtasia. Allows anything to be } \\
\text { clickable so learner can move seamlessly to a new screen or even outside the video to } \\
\text { additional learning materials. }\end{array}$ \\
\hline b & $\begin{array}{l}\text { Add-in to } \\
\text { PowerPoint }\end{array}$ & $\begin{array}{l}\text { Screen Capture of PowerPoint Presentation delivered in a micro-learning fashion and } \\
\text { combined with cursor highlighter to keep learner attentive. }\end{array}$ \\
\hline c & $\begin{array}{l}\text { Ability to Collect and } \\
\text { Report Test Scores }\end{array}$ & $\begin{array}{l}\text { Create Quiz and Collect Results via email. Organizes them and sends a daily report of } \\
\text { how students are doing, }\end{array}$ \\
\hline d & $\begin{array}{l}\text { Multiple video } \\
\text { Windows or Tracks }\end{array}$ & $\begin{array}{l}\text { Keep Learners attentive. Display screen recording inside one window, presenter } \\
\text { talking in another and an animation to go along with the screen recording in the third. }\end{array}$ \\
\hline e & $\begin{array}{l}\text { Green-screen } \\
\text { removal }\end{array}$ & $\begin{array}{l}\text { Overlay videos to create interesting learning scenarios. Need to avoid too many } \\
\text { moving parts that will distract the learner }\end{array}$ \\
\hline f & Call-outs & $\begin{array}{l}\text { Can be used to call attention to the learner on a key concept or call-to-action. Like } \\
\text { calling attention to the learner on an area on the video }\end{array}$ \\
\hline g & Cursor highlighter & $\begin{array}{l}\text { Can be used to keep interest to follow the animation of a hand-written sketch or text } \\
\text { similarly found in a whiteboard presentation... has potential for a Dopamine effect. }\end{array}$ \\
\hline h & Pan and Zoom & $\begin{array}{l}\text { Use to highlight an area of interest in the screen and to create variety in what's being } \\
\text { displayed and keep learner attentive }\end{array}$ \\
\hline i & Markers & Use to create a table of contents of portions of a long video \\
\hline
\end{tabular}

Table 2. List of Key Features in Camtasia \& Educational Use

The features enable the instructional designer to keep the learner attentive that includes establishing an interchange of actions between the student and the video. Screen capture with Camtasia has the advantage of requiring a relatively small initial capital investment and logistics when compared to a video recording studio. 
Based on the experience of Professor Santiago to teaching the laboratory content of EE110, she believes that more videos may be needed to provide additional help for students [3]. For online delivery, a problematic issue is helping students troubleshoot their circuits [3]. Hangouts, Skype or video chat sessions with either the instructors or with other students are possible solutions. Another means is the development of a troubleshooting checklist for students to follow before requesting instructor help.

Learner Control Principle. Breaking the content into smaller chunks allows the student to control their learning pace. Students must have enough time to process the information efficiently when the content is getting progressively complex. This will insure students do not overload their working memory and can effectively move the information into long-term memory. Once students grasp the content, they should be encouraged to move on to the next segment. To retain the learners' attention, the online lecture should be less than twenty minutes given by most TED talks and even less than ten minutes if it is a static screencast that does not show the instructor's face such as those YouTube videos found in Khan Academy.

Allowing the learner to control the pace of learning increases student engagement. Using video, students can pause or rewind if the content didn't make initial sense. The professor can simulate question and answer approach in a F2F classroom in an online environment by using interactive video. Student feedback found in Appendix A, shows that interactive video experimented during 2016 provides a more engaging experience and documented elsewhere by the authors [4].

Because watching a video is mostly a passive experience, the authors wanted students to have more interaction with the videos to increase engagement. In EE 110 for example, embedded questions were posted on top of the videos to simulate a Q\&A conversation with students. Interactions were added without redoing the 9 hours of 70-plus videos using web software, called $\mathrm{H} 5 \mathrm{P}$, described later in the paper. Questions can be randomly embedded in time throughout the video. The authors found that this random feature of embedded questions while having variety of content, adds an element of anticipation to engage the user to be attentive.

Positive results from the use of interactive video and Google Docs are shown in Appendix A. Student surveys were encouraging using both interactive video and Google Docs in delivering the multimedia content. The interactive video was used in EE110 to engage and allow learners to control pacing and content. Further details on these two implementations are documented in [4] and [5] by the authors.

Figure 1 provides an example of what is meant by an interactive video. The left screenshot shows the display of an interactive video before a student presses a knowledge check button. When a knowledge check activity appears on the video, the video automatically pauses. The pause cues or signals the student to act. As shown on the bottom of the left screenshot, the knowledge checks appear throughout the video at various times. This feature provides the student a level of suspense drawing attention to the media content.

The right illustration of Figure 1 shows the display after the student clicks on the button. The student must respond to the learning activity. After answering the question, the e-learner gets feedback. Also, the answers shown here are randomize in terms of the order. For example, 
1.33A shown on the top of the choices may appear on the bottom $0.75 \mathrm{~A}$ the next time the video is played. This random feature forces the learner to pay attention if the student decides to replay the video for review.

The interactive video includes clickable, clear and concise e-learning questions. In terms of mental rehearsal, several and short practice quizzes are given each week in preparation for weekly final quizzes and lab experiments.

Tips on Using Interactive Videos. Christopher Pappas [13] outlined some key tips when using interactive videos that are summarized below appropriate for the academic environment:

- Keep the interactive videos bite-sized so they are easily digestible and focused on a specific sub-topic

- Keep the focus on the speaker and avoid busy backgrounds and other distractions.

- Include clickable, clear and concise eLearning questions

- Try to include captions while giving complete control to learners so they can pause, rewind and adjust the volume

- Create an online companion guide and avoid computer-type manuals

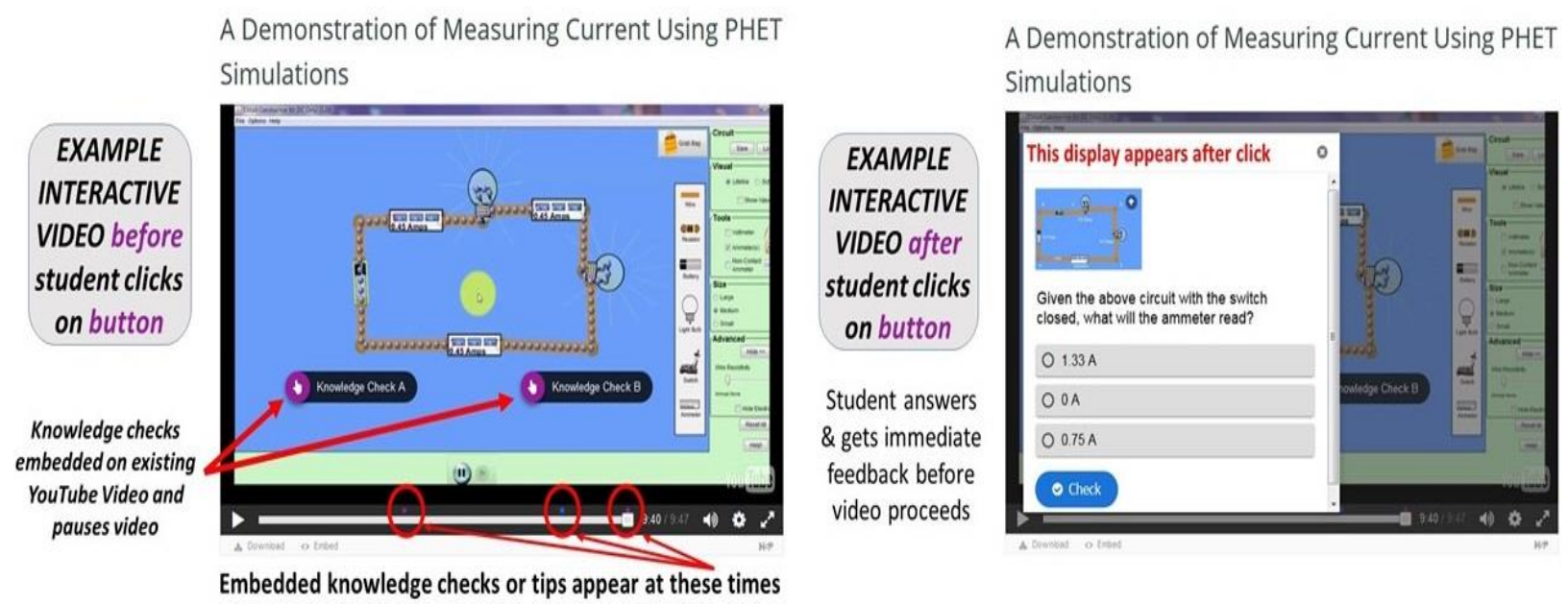

Figure 1. Example of interactive video of screenshots before and after student clicks on knowledge check button

The reader will notice that the above bullets has elements of CLT. EE110 followed the above guidelines as evidence on student comments in Appendix A. The last bullet helps reduce the effects of split attention, discussed in detail later in the paper. The online companion guide was not implemented for EE110 since students did not raise this as an issue. Pandey also outlined similar points to include: hotspots, drag-n-drop and fill-in-the-blanks [20] [21]. In addition, the above tips are consistent with extensive and comprehensive studies on multimedia e-learning [6] [7]. 
Interactive videos provide visual cues for the student learner when a different topic or activity begins or ends. This approach helps avoid overloading working memory.

Coherence Principle. Keep the content as simple as possible. Remove background music, animated backgrounds, decorative graphics and non-essential content that does not support the instructional goal. These elements may appear to make the learning more interesting but it increases the processing and extraneous load. Inessential content can distract the student as well.

As a general rule of thumb, stick to one audio channel and one visual for optimal learning [19]. When recording a lesson on your computer, keep a plain background on your desktop and avoid a busy wallpaper image. A cluttered work space can draw attention away from the important content intended for the student. These tips were used in EE110. When recording a computer screen with Camtasia, authors closed or removed all nonessential applications, browser toolbars, and desktop icons. Also, busy animated backgrounds were avoided in the video to follow the coherence principle. When installing Camtasia, an add-in is embedded within PowerPoint allowing direct use of Camtasia to eliminate extraneous background from the desktop when recording with PowerPoint.

However, green-screen techniques can cue the learner on important portions of the video or cue an important summary of the content that was previously presented [1]. The important point, is that the animations need to add value to the student's learning experience.

The animations in recorded videos of PhET simulations have been effectively used in EE110. As long as the multimedia content with animations and simulations are relevant, then they can add value to the student's understanding of the content.

This technique can be used as you animate a series of equations to derive a mathematical result. The authors found that animating a long series of equations with pauses and explaining what each equation means or having the students interpret what it means can increase student engagement and understanding of the material. For example, Table 3 shows some results from a sample of videos for math intensive applications in terms of likes, dislikes and number of views.

During 2008, before CoE developed EE110, Professor Santiago recorded videos to assess the instructional and online delivery of advanced and abstract engineering concepts. Results in Table 3 appear promising to develop future engineering courses using the instructional techniques found in this sample of videos. The experience gathered after 2008 in creating these videos was used to develop the multimedia content in EE110. Student surveys about the multimedia content for EE110 and its delivery can be found in Appendix A. These survey results appear to verify and validate the flipped learning approach or philosophy during the past few years.

The videos in Table 3 can be enhanced to further engage the student by embedding questions using: (1) interactive video or (2) highlight and cue relevant areas on the videos by Camtasia's video editing capabilities and educational features found in Table 2. The encouraging results of Table 3, increase Professor Santiago's confidence since there appears to be 'buy-in' from viewers allowing to proceed in presenting the multimedia approach to $\mathrm{CoE}$. 
The sample of narrated videos from Table 3 provides variety to engage the viewer including: (1) highlighted the cursor to engage the viewer, (2) animated equations in PowerPoints, (3) recorded animated PhET simulations and (4) experimentation of whiteboard animations. Providing variety in presenting the content will help engage the viewer or e-learner. A whiteboard animation records an artist drawing of a creative storyboard on a whiteboard. The whiteboard animation often has an audio lecture or speech to form a visual aid. A professor who has an audio recording can create a video using a whiteboard animation [18]. Like the videos in Khan Academy, the author has use Camtasia since 2008 to hand-write and derive equations on a writing tablet to emulate whiteboard animation.

When producing professional videos, the professor needs to practice, practice, and practice [19]. The professor needs to practice correctly moving the cursor or opening applications so they appear appropriately in the recording area. To get the proper screen recording, the professor needs to practice on positioning of browser windows and other applications [19].

YouTube provides a means to make the video the same size as well as being the same voice for Professor Santiago's YouTube Channel. These considerations are highlighted as well by TechSmith, maker of Camtasia [19].

\begin{tabular}{|c|c|c|c|c|}
\hline Video Title/Link & $\begin{array}{c}\text { Date } \\
\text { Uploaded }\end{array}$ & $\begin{array}{l}\text { Number of } \\
\text { Views }\end{array}$ & Likes & Dislikes \\
\hline $\begin{array}{l}\text { Signal Processing Tutorial: Discrete-Time Convolution } \\
\text { Examples (Inverse z-Transform) } \\
\text { https://www.youtube.com/watch?v=yzV3xW8YfzQ }\end{array}$ & 20 Apr 2008 & 30,279 & 67 & 3 \\
\hline $\begin{array}{l}\text { Matlab Examples - Review of Discrete Convolution using } \\
\text { Matlab } \\
\text { https://www.youtube.com/watch?v=bPAKMS6 FWg }\end{array}$ & 27 Apr 2009 & 44,829 & 71 & 6 \\
\hline $\begin{array}{l}\text { - Matlab Tutorial - Amplitude Modulation } \\
\text { https://www.youtube.com/watch?v=rH-EtQB8tPc }\end{array}$ & 25 Jun 2008 & 121,868 & 198 & 13 \\
\hline $\begin{array}{l}\text { - Operational Amplifier Tutorial - Basic Op Amp (Part) } \\
\text { https://www.youtube.com/watch?v=5GR8M5h-5H0 }\end{array}$ & 1 Mar 2009 & 250,683 & 515 & 25 \\
\hline $\begin{array}{l}\text { - Simulink / Matlab Video Tutorial and Example - Low Pass } \\
\text { Filter - Bode Plots (Part 2) } \\
\text { https://www.youtube.com/watch?v=Ehb0E_jObMk }\end{array}$ & $\begin{array}{l}3 \text { Jul } \\
2009\end{array}$ & 205,701 & 183 & 8 \\
\hline $\begin{array}{l}\text { - Thevenin \& Norton Examples - Tutorial on Thevenin } \\
\text { Equivalent Circuit Theory - Part } 1 \\
\text { https://www.youtube.com/watch?v=16MO8vIWuqo }\end{array}$ & 6 Mar 2009 & 147,009 & 161 & 28 \\
\hline $\begin{array}{l}\text { - Electric Current: Define Electric Current Flow With A Water } \\
\text { Analogy } \\
\text { https://www.youtube.com/watch?v=pcn6CNMJdzI }\end{array}$ & 5 May 2015 & 9,781 & 21 & 4 \\
\hline
\end{tabular}

Table 3. Sample Engineering Videos Using Camtasia as of 1 January 2018.

Split Attention Principle. The instruction should keep diagram/charts and detailed explanations on same page or screen within a short video. To improve information transfer, place text close to the corresponding graphic. Do not force the learner to visually scan the screen to match the text with the graphic since requires additional resources for mental processing. You can use cueing techniques to highlight key pieces of content. The professor can cue the student by highlighting important details. In a circuit schematic, the instructor can emphasize on the diagram by circling the component or provide an arrow of a key component. 
Composition and video editing software, like Camtasia, has many features to draw attention to key portions of the video. For example, the left figure of Figure 1 has a yellow semi-transparent circle following mouse movements. The student can then keep track of verbal explanations corresponding to highlighted areas from cursor movements on the video.

To minimize split-attention, CoE used other methods to help focus and engage the student in EE110. For example and before using interactive video, $\mathrm{CoE}$ used Google docs to provide a straightforward layout of a series of short videos and assessment quizzes so that students do not have to frequently jump back and forth between YouTube videos and assessment quizzes on word. The layout of YouTube videos and assessment quizzes is shown in Figure 2. Initial attempts used links to YouTube videos and links to word documents which can result in split attention. The authors have experimented with PowerPoint to embed YouTube videos followed with assessment quizzes. The authors have also experimented with embedding interactive videos within PowerPoint. The recording of student actions and collating results from quizzes gathered from interactive videos embedded in

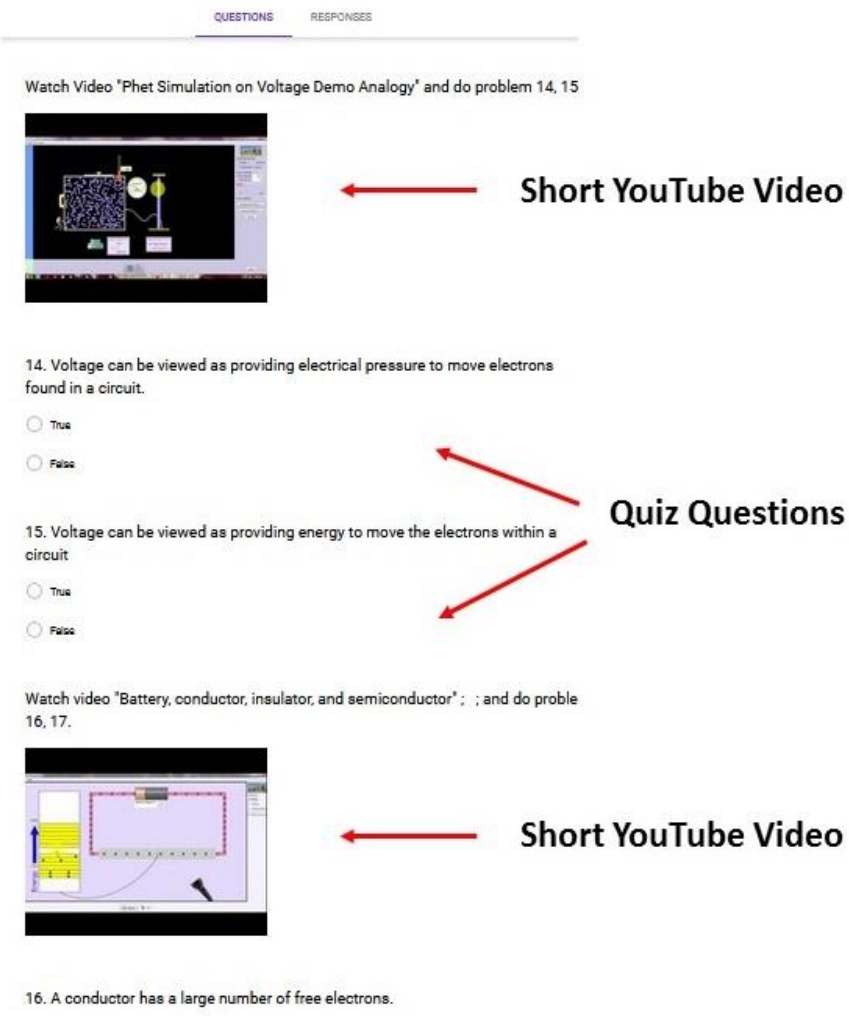

Figure 2. Screenshot of example Google Docs with embedded YouTube videos and quiz questions.

PowerPoint is work in progress. This is the primary reason to use the Google Docs approach which helps reduce the administrative burden for the authors associated with weekly assessments. Google Docs allow to easily collect weekly quiz results and export the results to an Excel spreadsheet.

Redundancy Principle. Do not narrate on-screen text. Audio and text duplication impedes learning and should not be confused with rehearsal which aids in automation [6] [7]. When the same information is processed through audio and visual channels, the learner is forced to process the same redundant information. However, narration of on-screen text appears appropriate when summarizing the content [6] [7].

Students learn best with graphics and narration better than with both graphics and on-screen text. Reading a lot of text with graphics on a single slide or screen is unsuitable for the student. Reading an extensive amount of text and understanding the graphics can lead to overloading working memory. If reading text is necessary, try not to have the student look for the essential text on a computer screen for example. Cue or highlight the essential text. 
Videos for EE110 did not have instructors reading text on the videos and comments on student surveys show reading on-screen text was not an issue. If fact, student comments from surveys from Appendix A reveal that there was a good mix of video and text in the multimedia course content.

Reversal Effect. In terms of reversal effect, freshman need worked examples while experts (e.g. seniors) may need less worked-out examples [6] [7]. To account for learner's prior knowledge, the proposed use of PowerPoint for adaptive learning is explained elsewhere [22].

As mentioned earlier, EE110 required intensive development of multimedia content and four full-time instructors. This freshman-level course required over seventy YouTube short videos, totaling about nine hours. Weekly online quizzes and weekly labs were performed in class to assess student understanding. For future development of traditional/online courses, CLT will be used for better instructional design and delivery.

CoE anticipates that less intensive development of multimedia content will be needed as students' progress through the program curriculum. For example, less videos may be needed for graduate level or senior undergraduate courses while more reflection type of learning activities may be required.

Self-Explanation/ Mental Rehearsal. During the last two years in EE110, the in-class and weekly lab experiments as well as weekly practice quizzes prepared for the final quizzes and labs. And these quizzes and labs proved effective to help transfer new knowledge and skills for long-term retention. As mentioned earlier with CLT principles, interactive video and Google Docs has been effectively used as well.

When students can perform hands-on lab experiments in class with instructor assistance in the troubleshooting process, the authors are confident that the multimedia content consisting of videos, text readings, homework and other assessment activities prepared the students to apply the learned content with hands-on lab experiments.

The online videos and quizzes provided individual space for students to reflect on the content. Giving students enough time to process the multimedia content prepared students to perform the weekly lab experiments.

Group activities include students helping each other collaborate and address lab procedures. Based on this observation, students performing the labs at home will be a challenge. The $\mathrm{CoE}$ plans to have a chat session to address questions about the conduct of the lab experiments. In terms of accountability for an online environment, $\mathrm{CoE}$ plans to have each student record short videos on their lab findings to verify and validate their understanding. Developing a concise and short video, takes a significant time for students to reflect on their weekly laboratory experience. In the F2F environment, students already give group presentations on selected labs in various engineering courses.

Students need to provide a short lab report on their findings to further internalize what they learned. Of course, full-blown lab reports will be expected on circuits and electronic courses after students have taken EE110. 
Discussion boards can easily provide individual student reflection and mental rehearsal. The techniques for reflective learning has been successfully used in a senior digital communications course [11]. Discussion boards for EE110 were also used but are complementary to the labs which were resulted in increased student workload. Recently, the discussion boards lacked participation in the discussion when adjuncts taught EE110 for the first time during the past year. The discussion boards will need to be investigated in the future in terms of reducing the level of effort and student workload.

It was mentioned earlier that interactive videos were used to engage students. The authoring suite used to engage students with variety of learning activities is called H5P. The authors intend to use the other H5P widgets to provide more reflective and self-explanation learning activities.

The H5P authoring suite is a free and easy-to use. H5P includes numerous widgets to allow students to reflect on what they viewed and what they learned. H5P widgets provides techniques allowing for self-explanation and mental rehearsal. The widgets intend to improve student engagement with the course material. For mobile learning, H5P uses HTML 5 and supports numerous mobile devices [23].

Table 4 lists the various interactive multi-media content found in H5P. Although not as versatile as other tools, it eliminates the cost for experimentation. A YouTube video can be enhanced with a variety of questions, text, pop-ups, and quizzes. Similar H5P services from other companies and used by some leading universities can cost at about $\$ 65,400$ per year for a platform version.

In addition to interactive video, $\mathrm{H} 5 \mathrm{P}$ has numerous other content types to deliver interactive course material [23]. Using the numerous H5P widgets makes the interactive content more engaging for students. The H5P authoring tool has been designed so that the content can be shared and reused. The types of content include widgets such as: games, multimedia, questions and social media. One widget is "course presentation". An instructor creates slides that are interactive on a webpage. Here, the educator can add text, audio, video and more. The instructor can even add gamification such as a board game. In this case, the user answers quiz questions to complete each level. The instructor can develop a question set. The question set can be a sequence of tasks engaging the user with multiple choice, drag and drop and fill in the blanks. Flash cards are also valuable for mental rehearsal so that learners can insert text corresponding to an image [17]. These content types provide a variety of interactive teaching modules to maintain student interest.

\begin{tabular}{|l|l|}
\hline \multicolumn{1}{|c|}{ Multimedia Content Type } & \multicolumn{1}{c|}{ Description } \\
\hline Interactive Video & Create videos enhanced with interactions \\
\hline Course Presentation & Produce interactive slides engaging students to act \\
\hline Image Hotspots & Overlay an image with multiple hotspots to provide info \\
\hline Timeline & Create a timeline of events with multimedia \\
\hline Find the Hotspot & Create hotspots for students to find \\
\hline Iframe Embedder & Embed a url or a set of files \\
\hline Appear.in & Add a video chat to a web page \\
\hline Chart & Generate bar and pie charts \\
\hline Impressive Presentation & Create a slideshow with parallax effects \\
\hline Collage & Create a collage of multiple images \\
\hline
\end{tabular}


Table 4. Samples of Multimedia Content Widgets in H5P [23]

Summary of CLT guidelines. Based on student comments from several end-of-course surveys found in Appendix A, the delivered content for EE110 followed key principles associated with CLT. Table 5 summarizes key principles and guidelines based on CLT [6] [7]. EE110 attempts to provide a positive learning experience for the freshman student. The above CLT principles found in Table 4 explain the instructional design for the course. To implement the flipped classroom approach, the authors have used a number of Camtasia's visual features to cue learners on important portions of a complex visual screen as well as using an e-learning authoring suite H5P to increase user engagement. The use of Camtasia, H5P widgets, YouTube social component, and Google Docs provided variety to deliver the content and assess student understanding in an attempt to reduce student boredom for the same mode of instruction.

\begin{tabular}{|c|c|}
\hline Principle & Guidelines \\
\hline $\begin{array}{l}\text { Modality } \\
\text { Principle }\end{array}$ & $\begin{array}{l}\text { - Working memory uses separate processing of visual and audio information (dual } \\
\text { encoding) }\end{array}$ \\
\hline $\begin{array}{l}\text { Learner } \\
\text { Control }\end{array}$ & $\begin{array}{l}\text { - Allow learners to control pacing and content } \\
\text { - Teach in segments and modules allowing for repetition or skipping as desired } \\
\text { - Teach support knowledge separately } \\
\text { - Teach Components before full systems }\end{array}$ \\
\hline Split Attention & $\begin{array}{l}\text { - Keep diagram/charts and detail explanation on same page to help student focus } \\
\text { attention (avoids split attention) } \\
\text { - Use visual cues and signals when content is complex } \\
\text { - Provide content summaries } \\
\text { - Avoid computer manuals }\end{array}$ \\
\hline $\begin{array}{l}\text { Redundancy } \\
\text { Effect }\end{array}$ & $\begin{array}{l}\text { - Avoid narration of slide text (audio and text duplication impedes learning) } \\
\text { - } \quad \text { Not to be confused with rehearsal or repetition aiding automation }\end{array}$ \\
\hline $\begin{array}{l}\text { Reversal } \\
\text { Effect }\end{array}$ & $\begin{array}{ll} & \text { Need to consider learner's expertise } \\
\text { - } & \text { Experts need less external instructional support } \\
\text { - } & \text { Novices need worked examples while experts do not } \\
\end{array}$ \\
\hline $\begin{array}{l}\text { Self- } \\
\text { Explanation/ } \\
\text { Mental } \\
\text { Rehearsal }\end{array}$ & $\begin{array}{l}\text { - } \quad \text { Learning activities to transfer new knowledge and skills for long-term retention } \\
\text { - } \quad \text { Mental processing of examples requiring clarification and elaboration } \\
\text { - } \quad \text { Wehearsal for maintenance or elaboration on problem solving instruction } \\
\text { Womple/problem pairs more efficient than all-practice lessons }\end{array}$ \\
\hline
\end{tabular}

Table 5. Some Key Principles and Guidelines of Cognitive Load Theory (CLT) [6] [7]

\section{Summary of Results Using the Flipped Classroom Approach for Winter 2016 to Fall 2017}

Table 6 shows the results of the grade distribution for the flipped classroom when compared to the traditional F2F classroom for course offerings of EE110. The left column shows the grade distribution, average percentage grade for the class, number of instructors, and delivery method. The grades were averaged for with and without including students who received an F. Instructor 1 (one of the authors) taught all the flipped classrooms during 2016 and F2F (or ground) course during Fall 2014 quarter. 
During 2014 and 2015, adjunct instructors taught the ground sections shown in the last three columns while the full-time faculty developed and refined the course content. The percentage grades found in the last three columns served as a comparison with the flipped classroom.

Table 6 also shows the average percentage grade (highlighted in yellow) when removing students with F-grades. For students who passed the course, the results show that the flipped learning approach was effective. The results from the 2016 Fall Quarter are comparable with the 2014 Fall Quarter results. Based on successful student feedback, the multimedia and interactive content appear to be satisfactory in preparing students to conduct the labs.

\begin{tabular}{|c|c|c|c|c|c|c|c|c|c|c|}
\hline & Fall2014 & Win2016 & Sum2016 & Fall2016 & Win2017 & Fall2017 & Fall2014 & Spr2015 & Fall2015 \\
\hline A & 5 & 3 & 1 & 3 & 2 & 3 & 1 & 2 & 3 \\
\hline B & 2 & 1 & 2 & 1 & 3 & 2 & 4 & 2 & 5 \\
\hline C & 1 & 1 & 1 & 1 & & & 4 & 1 & \\
\hline D & & 1 & 1 & & 2 & & & & \\
\hline F & 1 & 3 & 2 & 2 & & & & & \\
\hline w/o F & 90.6 & 85.5 & 83.0 & 88.8 & 82.1 & 90.8 & 82.7 & 88.1 & 87.7 \\
\hline w/F & 85.2 & 66.7 & 67.0 & 70.7 & 82.1 & 90.8 & & & \\
\hline Instructor & 1 & 1 & 1 & 1 & 5 & 4 & & 2 & 3 & 4 \\
\hline & & & & & & & & & \\
\hline DELIVERY & Ground & Flip & Flip & Flip & Flip & Flip & Ground Ground & Ground \\
\hline
\end{tabular}

Table 6. Summary of Grade Percentages from 2014 Fall Quarter to 2016 Fall Quarter

Instructor 1 taught one traditional (ground or F2F) and the F2F flipped classroom simulating an online environment. With the flipped classroom approach, there is an increase in the number of Fs when compared to the ground courses. Instructor 4 has taught the traditional and recently the F2F flipped learning approach. Although the student sample size is small, both approaches appear comparable in terms of grade outcomes. The intent is not to show which delivery method is better, but to see if the delivery of the flipped learning and its implementation as described by this paper can meet course outcomes.

The adjuncts (instructors 4 and 5 of Table 6) who taught EE110 using the F2F flipped classroom during 2017 were comfortable with the course content and that flipped learning approach met the course outcomes. However, the online discussion boards did not have much student participation according to the adjuncts. They commented that the discussion boards required extensive time and needs to be relooked. The authors agree that the online discussion boards did not support with the in-class lab and group activities. The authors plan to either eliminate or reduce the level of effort required on the discussion boards.

\section{Poor Performing Students and Next Steps}

The student receiving Fs resulted primarily from non-attendance in class and lack of submitted work. The authors further investigated the increase in the number of students receiving Fs summarized in Table 7. These results are consistent with the 2016 Winter Quarter survey by student six in Table A4 of Appendix A. The poor performing students did not like the flipped 
classroom. The flipped classroom requires the student to take on more responsibility, including: (1) viewing the multi-media content and completing assigned homework, (2) taking the weekly practice and final quizzes and (3) performing weekly hands-on experiments. Students who are more comfortable with the traditional F2F instruction may not be prepared for these responsibilities.

\begin{tabular}{|c|c|l|}
\hline Attendance & $\%$ Grade & \multicolumn{1}{c|}{ Comments } \\
\hline 20.0 & 7.6 & lack of attendance \\
\hline 47.6 & 12.4 & $\begin{array}{l}\text { lack of attendance and large number of assignment } \\
\text { receiving a grade of } 0 \text { points }\end{array}$ \\
\hline 50.0 & 37.0 & large number of assignments receiving a grade of 0 points \\
\hline 60.0 & 23.7 & large number of assignments receiving a grade of 0 points \\
\hline 70.0 & 34.1 & large number of assignments receiving a grade of 0 points \\
\hline 71.4 & 38.6 & large number of assignments receiving a grade of 0 points \\
\hline 80.0 & 36.1 & large number of assignments receiving a grade of 0 points \\
\hline
\end{tabular}

Table 7. Attendance and percentage grades from students who received an $\mathrm{F}$

For students who performed the assigned tasks, the multimedia content and assessment activities prepared them to do the weekly lab experiments. These activities are intended to develop and automate their schemas as they progress through program curriculum. In addition, weekly quizzes were given to assess their understanding and recorded through Google Docs.

During 2016 Fall Quarter, results from the use of interactive video and Google Docs are shown in Table 6 in the column labelled 'Fall2016'. Student surveys were positive about the use of interactive video as well as the delivery of multimedia content using Google Docs.

In terms of addressing poor performance by some students, CoE intends to look at SelfDetermination Theory (SDT). Research suggests that people are more motivated to do something if the learning experience satisfy their needs for autonomy (degree of independence, choice and control of self-knowledge), competence (degree of mastery of subject material), and relatedness (sense of belonging) [12]. How can professors support those with some simple changes to enhance the student's learning experience?

- Feedback: When providing student feedback, make the poor students feel respected who are capable of drawing the right conclusion. It may be that the poor students need more instantaneous feedback to address their wrong choice. The CoE briefly experimented with H5P when it comes to instant feedback which needs to be further implemented with text narrative in the future, especially when the course is delivered fully online. The assessment activities will help student become independent and give confidence to progress through the content with autonomy.

- Information: Student feedback from Appendix A show that the conscientious students do pull the information they need when they need it. This concept helps support their autonomy and lets them build competence at their pace. Professors need to provide resources for students to pull. All of the provided content need not be pushed to the 
students during the F2F or online learning environment. However, students need to be aware that the resources are available.

- "Voice" in learning. How can CoE make self-paced online activities feel more "human" to help people feel relatedness? One solution may be that interactive video and synchronous chat sessions will make the students feel more engaged in the learning activity. To promote relatedness, interactive video with narrative feedback can allow the learner to make the best choice. When the student sees a happy result (indicating competence and mastery of the material), narrative feedback can explain why it was the best choice and what was wrong with all the other choices. Due to time constraints in EE110, very little feedback in terms of text narrative was given in either interactive video or Google Docs when a student makes the wrong choice. The simulated chat session is intended to answer questions from the multimedia content and assessment activities. For online delivery, CoE intends to have two weekly chat sessions per week to address the questions from the multimedia content and the lab experiments. Student accountability will be important when instructor and students meet online synchronously.

\section{Conclusion}

Using CLT and leveraging CoE's teaching experience, the authors are attempting to find the best ways to help students store and retrieve information through either a F2F or online environment. In terms of future development of online courses, the authors will leverage experience from flipped learning and apply CLT to improve the design both the instructional content and its delivery. The e-learning principles include: modality principle, split attention, selfexplanation/mental rehearsal (lab activities), and learner control. CLT provides guidelines for better module design for efficient learning for either the online and F2F instruction.

Based on student comments in Appendix A, the delivered content for EE 110 followed principles and guidelines associated with CLT. Student feedback showed the use of Google Docs and interactive video are effective means to implement the flipped learning philosophy for either online or F2F teaching. The suite of tools provided by H5P requires further investigation to provide variety in delivering important engineering content in numerous ways. CoE anticipates the need for variety of content in engaging ways when future students do decide to pursue an undergraduate engineering program for several years in an online environment.

To address students who have received $\mathrm{F}$ grades from this study, Talbot [12] identified CLT, self-determination theory (SDT) and Self-Regulated Learning (SRL) to serve as frameworks for flipped learning. The authors intend to investigate SDT and SRL attempting to reduce or minimize the number of poor performing students. In the short-term, one simpler approach is to educate students on the flipped learning approach and its philosophy. Another consideration is to incrementally transition future courses to the flipped classroom on selected topics and on selected courses as students familiarize with the flipped learning concept. 


\section{Acknowledgements}

The authors would like to gratefully acknowledge Dr. Gail Cullen for her careful review of the paper. Her doctoral research, resources, and wisdom on the instructor attributes to provide and implement the flipped learning approach is sincerely appreciated and provided further inspiration in writing this paper.

\section{References}

[1] Santiago, John and Jing Guo, "Leveraging Internet Marketing Technologies and Green-Screen Techniques for Developing Engaging STEM and Onine Content (Update)," Transactions on Techniques in STEM Education, pp. 32-51, Jul- Sep 2017.

[2] Guo, Jing and John Santiago, "Flipped Classroom Method in Teaching Introduction to Engineering Course Online," in ASEE Rocky Mountain Section Conference, Cedar City, UT, September 2016.

[3] Guo, Jing, Kathy Kasley and John Santiago, "The Challenges of Teaching Engineering Labs Online," in ASEE Rocky Mountain Section Conference, Cedar City, UT, September 2016.

[4] Santiago, John and Jing Guo, "Introduction to Engineering Using Google Docs and Interactive Video in Support of an Online Flipped Classroom Approach," in ASEE Pacific Southwest Conference, Tempe, Arizona, April 2017.

[5] Santiago, John and Jing Guo, "Online Delivery of Electrical Engineering Courses Using the Online Flipped Classroom Approach," in 2017 Annual ASEE Conference and Exposition, Columbus, Ohio, June 2017.

[6] Clark, Ruth, Frank Nguyen, and John Sweller, "Efficiency in Learning - Evidence-Based Guidelines to Manage Cognitive Load," in Pfeiffer, San Francisco, CA, 2006.

[7] Clark, Ruth and Richard Mayer, "E-Learning and the Science of Instruction - Proven Guidelines for Consumers and Designers of Multimedia Learning (Third Edition)," in Pfeiffer, San Francisco, CA, 2011.

[8] Benedict, Benedict, "How We Learn - The Surprising Truth About When, Where, and Why It Happens," in Random House, 2010.

[9] Nilson, Linda B., Teaching at Its Best: A Research-Based Resource for College Instructors, San Francisco, CA: John Wiley and Sons, 2010.

[10] Gupta, Madhu S,Teaching Engineering: A Beginner’s Guide, New York, NY: IEEE, 1987.

[11] Santiago, John and Jing Guo, Developing an Entrepreneurial Mindset Using the KEEN Framework for a Digital Communication System Course (awaiting publication approval), in ASEE Annual Conference and Exposition, Salt Lake City, UT, 2018.

[12] Talbert, Richard, Flipped Learning - A Guide for Higher Education Faculty, Sterling, VA: Stylus Publishing, LLC, 2017.

[13] Pappas, Christopher, "Cognitive Load Theory and Instructional Design," 5 February 2014. [Online]. Available: https://elearningindustry.com/cognitive-load-theory-and-instructional-design. [Accessed 2017]. 
[14] Hendricks, David, "Cognitive Load Theory, How Do I Apply It?," Google, 17 April 2016. [Online]. Available: https://www.youtube.com/watch?v=stJ-MkTgRFs . [Accessed Nov 2017].

[15] Guyan, Matthew, "5 Ways to Reduce Cognitive Load in Elearning," elearningindustry.com, 1 November 2013. [Online]. Available: https://elearningindustry.com/5-ways-to-reduce-cognitive-load-in-elearning. [Accessed Nov 2017].

[16] J. Cavalier, "Introduction to Microvideo," elearninglearning.com, 21 February 2017. [Online]. Available: http://www.elearninglearning.com/camtasia/cognitive/?open-article-id=6245237\&article-title=introductionto-microvideo\&blog-domain=techsmith.com\&blog-title=visual-lounge. [Accessed 14 January 2018].

[17] Mayer, Richard, Cognitive theory and the Design of Multimedia Instruction: An Example of the Two-way Street Between Cognition and Instruction, Also retrieved from: https://www.youtube.com/watch?v=stJMkTgRFs : EBSCO Publishing (Wiley), 2002.

[18] Harvard University, "Online Learning is Different, Harvard Study," 4 April 2013. [Online]. Available: https://www.sciencedaily.com/releases/2013/04/130404122240.htm. [Accessed 2017].

[19] Perry, Andrew, "4 Types of Videos For Learning," elearninglearning.com (TechSmith Blog), 21 March 2017. [Online]. Available: http://www.elearninglearning.com/camtasia/cognitive/?open-article-id=6350420\&articletitle=4-types-of-videos-for-learning \&blog-domain=techsmith.com\&blog-title=visual-lounge. [Accessed 14 January 2018].

[20] A. Pandey, "Using Interactive Videos for Learner Engagement," elearningindustry.com, 23 August 2016. [Online]. Available: https://elearningindustry.com/interactive-videos-for-learner-engagement. [Accessed 2016].

[21] Pandey, Asha, "Free ebook: How to Use Interactive Videos for Learner Engagement and Supercharge Your Online Training," elearningindustry.com, 7 March 2017. [Online]. Available: https://elearningindustry.com/use-interactive-videos-for-learner-engagement-supercharge-online-trainingfree-ebook. [Accessed 2017].

[22] Santiago, John and Jing Guo, "Embedding YouTube Videos and Interactions in," in Annual ASEE Conference and Exposition, Columbus, OH, 2017.

[23] h5p.org, "Examples and Downloads," h5p, [Online]. Available: https://h5p.org/content-types-andapplications. [Accessed 2016]. 


\section{APPENDIX A. Student Feedback}

Table A1 shows the student feedback when implementing both Interactive Video and Google Docs for flipped learning. Both methods were effective, especially interactive video (Question 2), based on feedback.

Interactive video where knowledge checks (e.g. quizzes) were embedded throughout the video requires less resources in working memory. Using Google Docs approach, the students need to view the entire short video before answering the questions. This approach may require more resources in working memory. The Google Docs approach appear not to overload working memory.

\begin{tabular}{|c|c|c|c|c|c|}
\hline $\begin{array}{l}\text { Survey Questions for EE110, Introduction to Engineering } \\
\text { (1-Strongly Disagree, 2-Disagree, 3-Neutral, 4-Agree, 5-Strongly Disagree) }\end{array}$ & 1 & 2 & 3 & 4 & 5 \\
\hline 1. The teaching methods in this course are effective. & & & & 3 & 6 \\
\hline $\begin{array}{l}\text { 2. Interactive video with embedded knowledge checks enhance } \\
\text { engagement for the student when viewing the video. }\end{array}$ & & & & 1 & 8 \\
\hline $\begin{array}{l}\text { 3. Quizzes in Google Forms (or Docs) format enhance engagement } \\
\text { for the student when viewing the video and then answering } \\
\text { questions. }\end{array}$ & & 1 & & 2 & 6 \\
\hline $\begin{array}{l}\text { 4. The interactive video and assessment approach (Google Forms) } \\
\text { provided an effective approach to teach engineering topics for } \\
\text { either the traditional face-to-face teaching or online teaching }\end{array}$ & & & & 4 & 5 \\
\hline
\end{tabular}

Table A1. Student Survey of Teaching Approach in 2016 Fall Quarter

Table A2 shows the corresponding student comments from Table A1 for Fall 2016 Quarter. The observations attempts to relate their comments to Cognitive Load Theory (CLT).

Observations of student comments for Question 1.

- Students liked the format when the video focused one or two points. This comment reveals that student's capacity of working memory was not exceeded.

- One student liked the ability to rewind a video to increase their understanding. This shows that students like to control the pace of their learning. Again, this avoids exceeding capacity of working memory.

- The mimicking the online flipped learning came close to traditional F2F learning. The delivery method of the content appears to follow CLT guidelines.

Observations of student comments for Question 2.

- Students enjoyed the interactive video to keep them engaged and to prevent their mind from wandering using knowledge checks (quizzes). This aspect relates to the CLT principle of cueing (or Split Attention) to signal the learner to pay attention. 


\begin{tabular}{|c|c|}
\hline 1. The teaching methods in this course are effective: & \\
\hline \multicolumn{2}{|l|}{ The evaluations through the video really help to reinforce concepts covered in the lecture. } \\
\hline \multicolumn{2}{|l|}{$\begin{array}{l}\text { I liked the way that the lectures focused on just one or two points and thoroughly explained them. I also } \\
\text { liked that if there was a topic that I did not understand immediately I could rewind the video and view the } \\
\text { material again. }\end{array}$} \\
\hline \multicolumn{2}{|l|}{ The teaching methods were as effective as they could be with out a face to face. } \\
\hline \multicolumn{2}{|l|}{ I enjoy the quiz style for the extra credit as well } \\
\hline \multicolumn{2}{|l|}{ 2. Interactive video with embedded knowledge checks enhance engagement for the student when viewing the video: } \\
\hline \multicolumn{2}{|l|}{ More video lectures should be setup like this. } \\
\hline \multicolumn{2}{|l|}{$\begin{array}{l}\text { I find that when I watch a long video or a video lecture it is easy for my mind to wander or } \\
\text { felt that the knowledge check kept my mind from wandering and helped me to focus on the } \\
\text { points of the topic. }\end{array}$} \\
\hline \multicolumn{2}{|l|}{ The } \\
\hline \multicolumn{2}{|l|}{$\begin{array}{l}\text { 3. Quizzes in google forms format enhance engagement for the student when viewing the video and answering the } \\
\text { questions }\end{array}$} \\
\hline \multicolumn{2}{|l|}{ The quiz question formats used are excellent and easy to understand. } \\
\hline \multicolumn{2}{|l|}{$\begin{array}{l}\text { I found that just knowing that there was going to be a quiz made me want to make sure I understood } \\
\text { topic at hand. I also thought that to see the material and then be given a question about it made sure } \\
\text { was understanding what the main points were and that I understood the types of examples to displa) } \\
\text { knowledge. I also liked having the answers for questions that I missed so I could go back to the video } \\
\text { look in the book to find out how to get the correct answer. This gave me much more confidence in my } \\
\text { understanding of the material. }\end{array}$} \\
\hline \multicolumn{2}{|l|}{$\begin{array}{l}\text { 4. The interactive video and assessment approach (Google Forms)provided an effective approach to teaching } \\
\text { engineering topics for either the traditional face-to-face teaching or online teaching: }\end{array}$} \\
\hline \multicolumn{2}{|l|}{$\begin{array}{l}\text { Both online and ground classes should have access to these videos. Doing so could allow more time for in } \\
\text { class discussions on more complex topics. }\end{array}$} \\
\hline \multicolumn{2}{|l|}{$\begin{array}{l}\text { This is definitely helpful since I have taken the EE110 and was required to watch the whole video and then } \\
\text { answer the questions. I feel putting the questions in the video immediately after the topic is covered helps } \\
\text { the user to retain the information better as well as stay engaged. }\end{array}$} \\
\hline \multicolumn{2}{|l|}{$\begin{array}{l}\text { I thought that the interactive video and assessment approach did provide an effective approach to teaching } \\
\text { the topic. I think that watching the videos combined with reading the book and completing homework will } \\
\text { give the student a thorough understanding of the topic. I am primarily a ground student and I think that } \\
\text { these interactive videos would be a valuable tool for a ground class also. I find that a student can never } \\
\text { have enough resources to reinforce the knowledge given in class. If a student is having trouble grasping the } \\
\text { concepts of a class fast enough these videos would be invaluable. }\end{array}$} \\
\hline \multicolumn{2}{|l|}{$\begin{array}{l}\text { The videos would greatlyenhance a traditional class and definitely make online classes a more feasible } \\
\text { option for online classes. }\end{array}$} \\
\hline Although the google form learning style can be effective, sometimes it is possible for a student to pass & \\
\hline
\end{tabular}

Table A2. Student Survey on Teaching Methods for 2016 Fall Quarter

\section{Observations of student comments for Question 3.}

- Questions were clear and concise.

- The suite of multimedia provided to the student ensured that students who make an effort will understand the material. This involves the Principle of Learner Control. Providing immediate feedback on assessment questions is a positive feature appreciated one student.

\section{Observations of student comments for Question 4.}

- The Flipped Learning methods can be both effective for both online and F2F.

- Learner control and variety of multimedia content are key components to the flipped learning approach.

- The flipped learning approach can serve as an approach to translate F2F for online.

- Order of answers should be randomized for multiple-choice questions. 
Table A3. At the end of the 2016 Winter Quarter, Chair and Dean of Engineering College held a "Pilot Focus meeting" that served as an end-of-course feedback. The course instructor was not present in the meeting to promote more open student feedback. Students in the pilot class were interviewed about the effectiveness of the pilot course. Four out of Ten students in the class attended that meeting. The notes in Table A3 below are to summarize the student feedback.

1. Errors in the course are distracting said one student; but the student consensus was that the errors are very few in this course.

2. The myDAQ-based lab equipment is very effective notwithstanding the issues of which we were aware such as insufficient drive current from the myDAQ internal power supply and the need for an external digital multi-meter to complement the internal one so that both voltage and current may be measured simultaneously. One student said that he noted a distracting lag between his commanding a function and the realization of that command.

3. Videos and slide sets are well done and useful. There is a good balance between paper and online content.

4. The problem assignments are well done and useful.

5. One student said that the course is very intense. Snow days should not be allowed. You fall behind.

6. They wondered if online labs would be as effective as those done in class live and in person. There is a lot of person-person interaction in solving the problems with the labs. Kathy noted that if students will attempt the labs ahead of time and bring their issues to the chats, it should work well.

7. In response to one question as to whether they believed there might be a bias in industry against engineers who obtained their degrees online, they opined that there should not be but probably is. But they also said they are not yet engineers, do not work in those circles, and therefore do not know.

Table A3. Summarized notes in the Pilot Focus Meeting for 2016 Winter Quarter

Table A4 shows Student Feedback for the first implementation of the flipped learning approach as a pilot program. Students 1-5 had useful comments and Student 6 was not thrilled with the flipped learning approach. CoE intends to provide more explanation of the flipped learning approach as well as how learning takes place based on CLT. 


\begin{tabular}{|c|c|}
\hline Student \#1 & $\begin{array}{l}\text { "In this class I got a better understanding of many electronic theories then what I have gotten in classes before this one. I } \\
\text { believe that I should have taken this class before some of the classes like Digital Design } 1 \text { and Circuits } 1 \text {. If I had taken } \\
\text { this class, I do not think that I would have struggled as much in the other classes. What I have learned in this class gave } \\
\text { me a better understanding of logic gates, circuit design, and testing circuits. I have realized in this class that I really like } \\
\text { putting the function generator together and seeing that it works. I now know that I need to improve on my soldering } \\
\text { skills. To me that was the best part of the class. } \\
\text { For me the most challenging part of the class was doing Boolean Algebra and soldering the function generator. Once the } \\
\text { labs get updated for MyDac I think this class will be great. I think everyone in the class should have to buy one to be able } \\
\text { to do homework and labs. Sometimes work interferes with my school schedule or if you get sick you can still keep up } \\
\text { with the labs from home. Overall I believe this class is very informational I learned a lot and now I have a better } \\
\text { understanding of circuits." }\end{array}$ \\
\hline Student \#2 & $\begin{array}{l}\text { "To be perfectly honest, I already knew most of the material in this class. However, working on only analog equipment } \\
\text { in the past, the material on digital circuits and Boolean algebra was new. I enjoyed this portion of the class and learned a } \\
\text { lot. I look forward to learning more in this area in future courses." }\end{array}$ \\
\hline Student \#3 & $\begin{array}{l}\text { "This was a great course; I would have to say since we actually learned about Circuits and were able to build them in } \\
\text { labs. This is very helpful since I took a class prior to this and I was somewhat lost. I think if I had taken this course first I } \\
\text { would have had a better grasp on the topic. Along with the fact that I took a higher level course the Boolean algebra is } \\
\text { something that I did expect to learn in this class. The teacher did a great job of showing little tricks in order to simplify } \\
\text { circuits. Through the entire course I found only one thing to be challenging and that was definitely the Boolean algebra. } \\
\text { The short cuts and things that we were taught were very helpful but it was definitely a very challenging topic. Finally the } \\
\text { one thing that I did learn that I can and will use in future courses are how to trouble shoot a circuit that isn't working } \\
\text { properly. } \\
\text { Overall, I feel that this is a great class to have prior to any other courses in order to get a solid foundation and } \\
\text { understanding of what's going on now and in the future." }\end{array}$ \\
\hline Student \#4 & $\begin{array}{l}\text { "When I started this course I didn't expect lower level math to be involved. I was surprised to learn that I was able to } \\
\text { take to Ohm's Law very well as it became a staple for the rest of the term. I also didn't expect that simulations would } \\
\text { play a major role to understand the basics of engineering. I was surprised to find out how well the simulations explained } \\
\text { the validated things like electric fields. I expected out of this course was for it to be somewhat difficult to complete if I } \\
\text { wasn't able to show up to every class. } \\
\text { What I found to be the most challenging in the course was the transition to online which had it bugs. I would assume that } \\
\text { since we were the first class tested under these conditions that the next time around it won't be half in class and half } \\
\text { online. I would say in order to be successful without any hiccups next term the issues like not being able to upload } \\
\text { assignments should be fixed. I would also say that you would also need to just proofread all of the assignments to ensure } \\
\text { that different values aren't referred to like it initially asking for a } 5 \text { ohm cap and at the very bottom of the paper saying } \\
10 \text { ohms. All in all I really did enjoy this class and felt it would be a great step toward someone that is going to work in } \\
\text { the engineering field. " }\end{array}$ \\
\hline Student \#5 & $\begin{array}{l}\text { "I was very happy to have this class as an introductory class into engineering. It shows that there is a lot to learn yet } \\
\text { achievable with enough studying. One thing that I was pleasantly surprised was the building of the signal generator. I } \\
\text { really like how it was hands on and with a few short weeks of class you understood what all the components do as you } \\
\text { then solder them into place on the signal generator. I expected to have a brief understanding of the components prior to } \\
\text { the class but was surprised to learn how in depth we got with them. } \\
\text { I found that the most challenging aspect was the application process once all the information is given then applying that } \\
\text { to the lab. Sometimes it was easy but me being a complete amateur at building on the bread board it was one thing to } \\
\text { learn about it but then completely different once given the bread board to test it. To improve in my next course I plan on } \\
\text { using my brief understanding of the how the bread board works and to always test or model you circuits before applying } \\
\text { them. " }\end{array}$ \\
\hline Student \#6 & $\begin{array}{l}\text { "I really had higher expectations for this course than what I got out of it. I expected in depth lectures and knowledge on } \\
\text { basic electronics but what I got were recorded videos that did not fully explain the concepts and labs I was tasked to } \\
\text { complete without prior guidance as to what we were testing. I expected that test equipment such as multi-meters and } \\
\text { oscilloscopes would be introduced, operations explained, and then had their functions demonstrated so that we could } \\
\text { continue to build upon these tools through our electronics careers. } \\
\text { The challenges for me were interpreting the labs especially when a couple of them had unclear objectives of what we } \\
\text { were meant to accomplish. There were also errors in the labs which suggest that they had not been tested. In our first lab } \\
\text { the wires in the photos were in the incorrect positions of the board, yet if this lab had been constructed and tested... } \\
\text { shouldn't it have easily been identified that the wires were wrong before the photos were taken because the LEDs would } \\
\text { have failed to light." }\end{array}$ \\
\hline
\end{tabular}

\section{Table A4. Student Feedback for 2016 Winter Quarter.}




\section{APPENDIX B. List of Abbreviations and Acronyms}

ABET - Accreditation Board for Engineering and Technology

CLT - Cognitive Load Theory

$\mathrm{CoE}$ - College of Engineering

CTU - Colorado Technical University

EE110 - Electrical Engineering 110 (Introduction to Engineering)

F2F - Face-to-Face

H5P - HTML 5 Package

HTML - Hypertext Markup Language

Matlab - Matrix Laboratory

myDAQ - my Data Acquisition. A low-cost data acquisition from National Instruments.

SDT - Self-Determination Theory

SRL - Self-Regulated Learning 